\title{
Experimental Evaluation of Gas Filled Plenum (GFP) Insulation for Ducts
}

\section{LBNL 52084}

\author{
lain Walker and Cyril Guillot \\ Energy and Environmental Technologies Division \\ Lawrence Berkeley National Laboratory \\ Berkeley, $C A$ \\ January 2003
}

\section{INTRODUCTION}

Forced-air heating and cooling system ducts are often located outside conditioned space in US houses. For these systems to perform efficiently it is important that these ducts be well insulated. Common practice is to use a glass fiber wrap around the ducts - either field applied or more commonly, integrated into a flexible duct. Most duct insulation has an R-value of 4.2, with R6 and R8 ducts also occasionally used. With glass fiber insulation being about R4 per inch (RSI $0.28 / \mathrm{cm}$ ), this adds 2 to 4 inches $(50$ to $100 \mathrm{~mm}$ ) to the duct diameter. Some building codes are now requiring these higher insulation levels, for example, the EPA requires the use of R6 ducts (for Energy Star ducts: http://www.epa.gov/hhiptool/PDF/Duct_Spec 2002.PDF), and International Energy Conservation Code (BOCA 2003) requires R8 ducts. The difficulty with adding insulation to ducts is the increase in diameter of the ducts that makes them expensive to transport because they take up a large volume and are difficult to install in the confined spaces available for ducts in houses.

The objective of this study was to evaluate Gas Filled Plenum (GFP) technology as an alternative duct insulation. GFP ducts have the potential to provide greater insulation levels than existing ducts (for a given thickness of insulation or size of duct) and provide cost savings in transportation. These transportation cost savings are based on the idea of shipping the GFP ducts empty and inflating them on-site. To evaluate this technology for ducts we constructed a prototype duct and determined both its flow and heat transfer resistance in LBNL's duct testing laboratories.

The GFP technology works by encapsulating a gas (usually air - but other noble gases such as Argon or Krypton can provide significant increases in thermal resistance with increased cost) in a metalized film jacket. A honeycomb structure is used to keep individual gas pockets small to minimize convection heat transfer. A metallic finish (usually aluminum) minimizes radiation heat transfer between the surfaces.

\section{GFP DUCT PROTOTYPE}

GFP panels are constructed from multiple layers of thin materials (usually plastic) that trap air (or other gases) between each layer, as illustrated in Figure 1. The material surfaces are usually covered with a metallic reflective film that reduces radiation heat transfer. It is common to divide the air gap into several spaces. This is usually achieved by using heat to fuse the layers of plastic material together to form seams between the air spaces. In existing commercial applications, the seams are often offset between adjacent layers to avoid thermal bridging effects. Because the fusing process does not work well when the surfaces are metallized, the raw material plastic sheets are often striped with alternating metallized and bare surfaces, with the bare surfaces used to provide the seals between the air gap spaces. In all the samples used in this study the air gap spaces were about one inch $(25 \mathrm{~mm})$ wide, with fused sections about one quarter of an inch $(6 \mathrm{~mm})$ wide. Commercially available disposable shipping liners are expected to stay lofted for at least 3-5 days (and some do much better) but are not necessarily optimized for long-term gas retention. Our prototype had problematic seals that meant some sections leaked rather quickly within a day or two of filling. With additional work it would be possible to improve the gas tightness of the GFP duct, however the positive pressure configuration is unlikely to be reliable for the 20 - to 30 -year lifetime that would be required of a duct system. Previous studies tested panels under neutral pressure (surface area not constraining volume), and found that they held up for 10+ years, including inert gas fills like Argon. A GFP duct with neutral 
pressure would have to rely on another structural element for lofting (e.g., a standard flex duct core) and the insulation itself would need to define its volume with some springy stiffness.

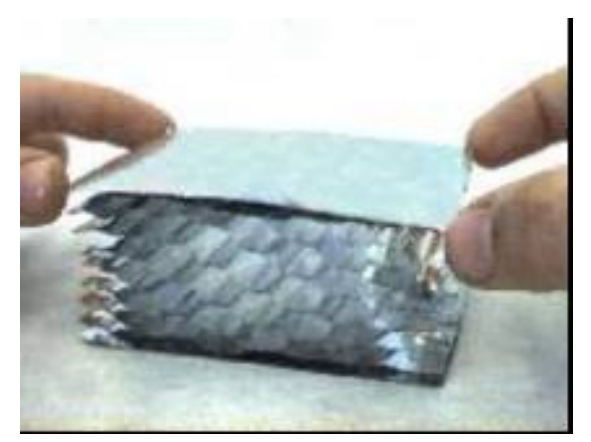

Figure 1. Example of multilayered GFP (Photo: Goudey, LBNL)

Initial samples of GFP duct were constructed by hand in various geometries, including longitudinal sections, concentric rings and a continuous helix. All of the samples were round ducts, rather than rectangular, because the ducts used for comparison and most ducts installed outside conditioned spaces (where insulation is most important) have a round cross section.

For the longitudinal construction, the seams separating the gas filled spaces are parallel to the axis of the duct. Figure 2 shows a sample duct section constructed using this technique. A flat panel is constructed and two sides joined to form a hollow tube about 20 inches $(50 \mathrm{~cm})$ in length. The width of the flat panel, and therefore the number of gas filled spaces, determines the diameter of the resulting tube. Building panels of different widths allow different diameter tubes to be nested (as shown in Figures 2 and 3), so as to build up several concentric layers of gas filled panel. The length of each section was limited by the machine used to manufacture the GFP and the dimensions of the raw material used in the panel. Although GFP construction requires metallized surfaces to reduce radiant heat exchange between the GFP surfaces, we also used some plain materials without metallization, as shown in the right-hand illustration in Figure 3. The non-metallized samples allowed us to vary the spacing of the sealed strips that separate each gas filled space to change the flexibility of the panel. This flexibility is important because closer spacing between sealing strips means that there is more seam area compared to gas filled area. The seams have negligible heat flow resistance compared to the gas filled sections, thus additional seams lead to lower overall insulation value for the GFP. Too large a spacing led to the resulting panels being very difficult to form into round cross section ducts. For example, if only five seams were used the duct tends to form a square cross section with a seam at each corner. Lastly, we also tried to form the panels into a concentric spiral, but the material was difficult to form into this shape. It required wider sections than we were able to manufacture because enough material for three or four layers needs to be made in one continuous piece. Lastly, the changing internal and external diameters (required using this technique) made it difficult to line-up the non-metallized sections when forming the individual air spaces.

Using this longitudinal construction method would require some sort of duct liner for any bends in the duct because the duct tends to fold sharply rather than bend smoothly. Thus this construction method is suitable only as an insulation replacement rather than a stand-alone duct. An advantage of the longitudinal construction method is that the fused sections that have little insulation value can be arranged so that they are always covered by a nonfused section, otherwise thermal bridging could occur if a single layer of GFP were used. 

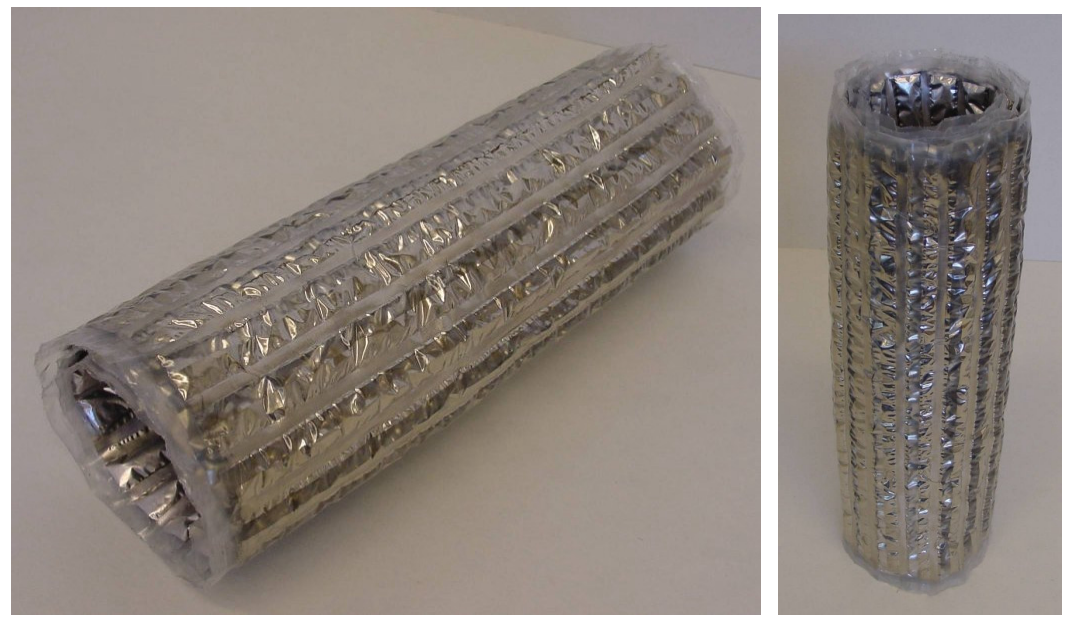

Figure 2. Sample GFP duct section using longitudinal seams and concentric tubes (Photo: Goudey, LBNL)
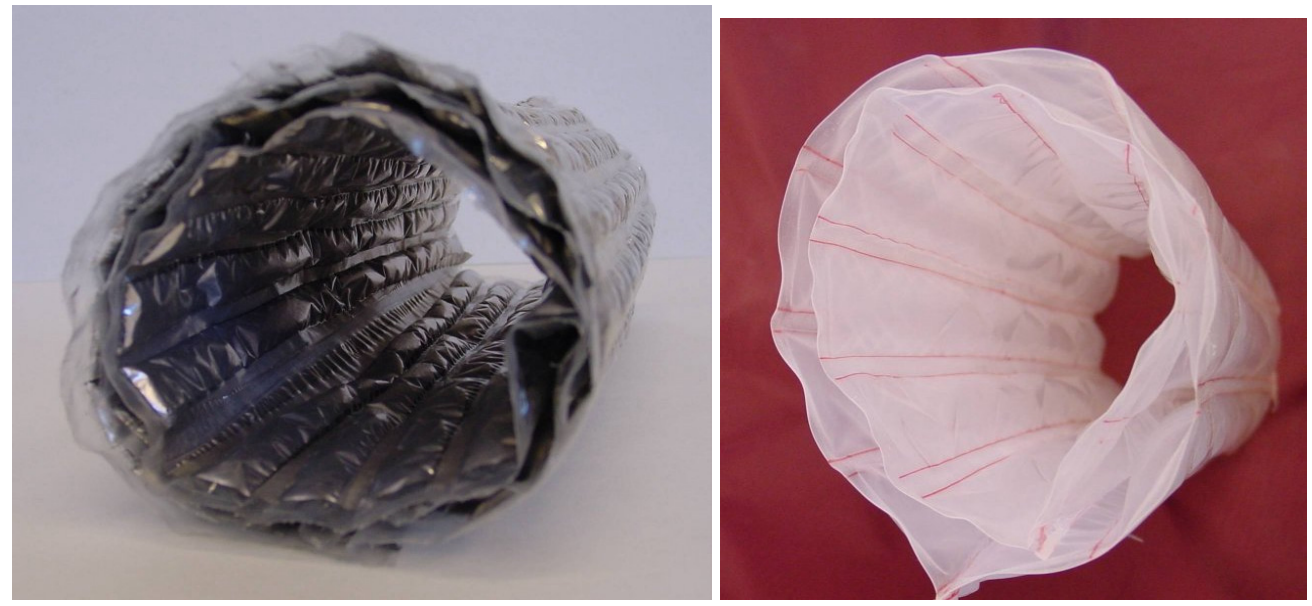

Figure 3. End view of longitudinal GFP duct sections: metallized on the left and non-metallized on the right. (Photo: Goudey, LBNL)

A second construction technique was to fabricate slices of duct made of concentric rings, and then assemble these slices to make a continuous duct. This method has the advantage that the full insulation thickness required can be assembled in one piece rather than the separate concentric sections required using the other techniques. Figure 4 illustrates a small sample of this technique. Each slice of duct made this way required inflation, which added to construction time compared to the other techniques. These samples produced a relatively rigid duct that was very difficult to bend. The bending limit for these ducts is a result of the requirement to stretch the external radius of the bend and compress the internal radius. In particular, the compression results in collapsed air gaps and would lead to poor insulation. Using this construction method leads to an accordion shaped duct that would have little thermal resistance at the joins between each ring. Lastly, the internal surface of the duct would consist of a series of seams perpendicular to the air-flow, resulting in very high flow resistance. For these reasons (but chiefly the difficulty in constructing enough material to test), we did not produce a large duct for thermal testing. 

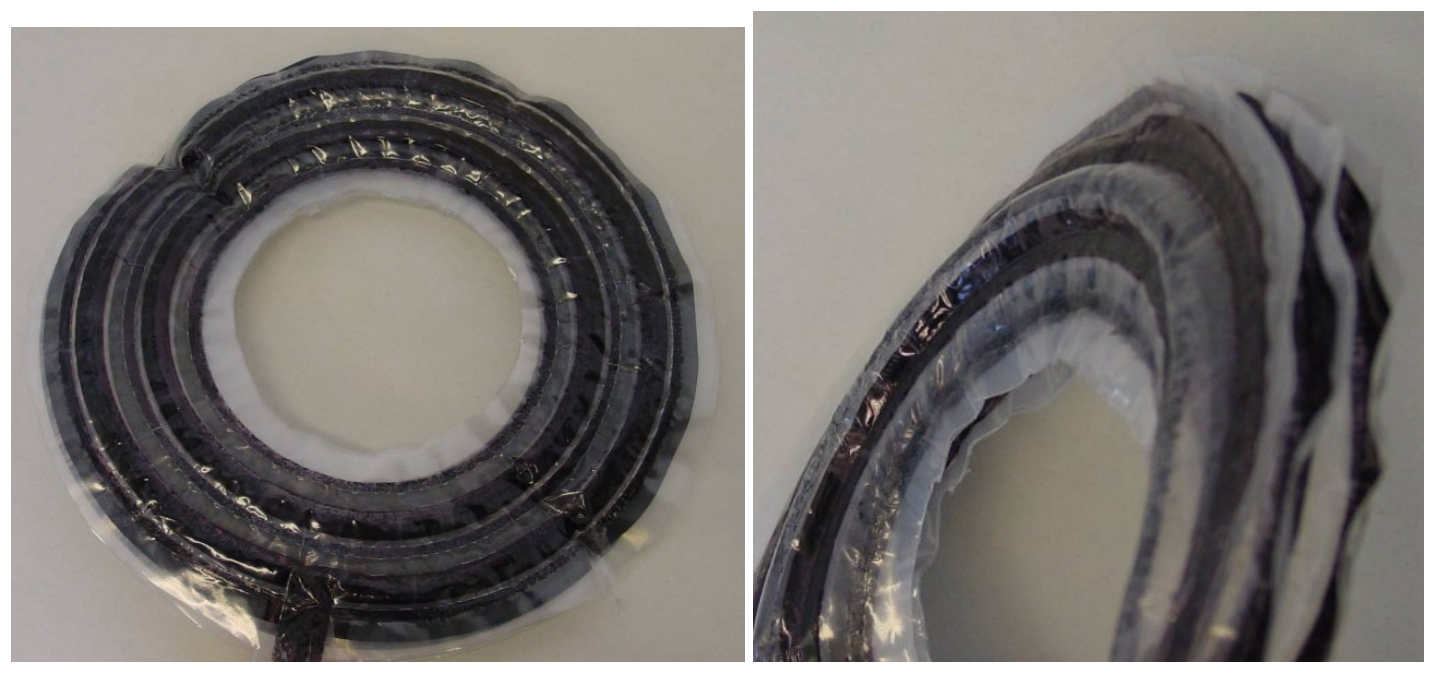

Figure 4. Concentric ring example GFP duct section. (Photo: Goudey, LBNL)

Another alternative construction technique was to fabricate a helix made from a single continuous air filled gap about one inch $(25 \mathrm{~mm})$ wide. Figure 5 shows a small sample of this duct construction method. Initial fabrication showed that the gas filled spaces tend to fold sharply, resulting in an uneven shape, rather than maintaining a round duct cross section. Subsequently, the construction method was changed to divide the air filled gap every few inches (centimeters) with another seal.

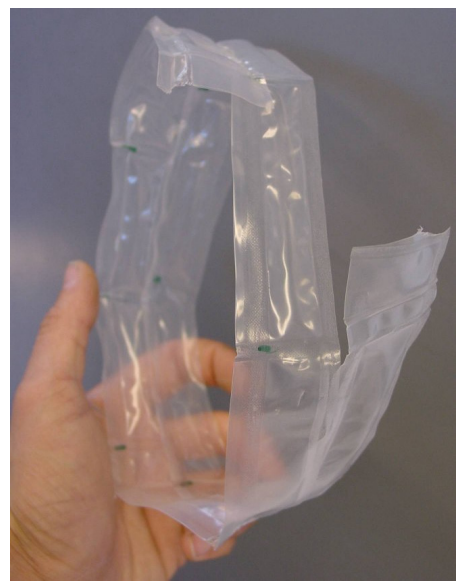

Figure 5. Helical construction for GFP duct sample. (Photo: Goudey, LBNL)

After examining these initial samples, it rapidly became clear that it would require too much effort to produce sufficient quantity of GFP duct using any of these construction methods. As an alternative, the prototype GFP duct was constructed using sections of commercially available GFP duct insulation used for insulated packaging containers. This standard packaging material is flat and shaped to form a cube when folded up. We cut and reformed this material to form tubular duct sections of 6 inch $(150 \mathrm{~mm})$ I.D., each about $2 \mathrm{ft}(600 \mathrm{~mm})$ in length. Several sections were assembled to form a longer section for our experiments. The length of the test section was limited by the available laboratory space (and the labor intensive construction of the GFP duct) to $17 \mathrm{ft}(5.2 \mathrm{~m})$. Figure 6 is a photograph of a section of the GFP prototype duct that shows how the duct (in white) is taped into a tube and then connected to other tubes using red tape. For comparison, we tested the GFP duct in its uninflated state to give an indication of potential insulation degradation if the gas filling is lost from the GFP, as well as testing a standard flexible duct with R4.2 (RSI 0.7) glass fiber insulation, and an uninsulated metallized plastic flexible duct. 


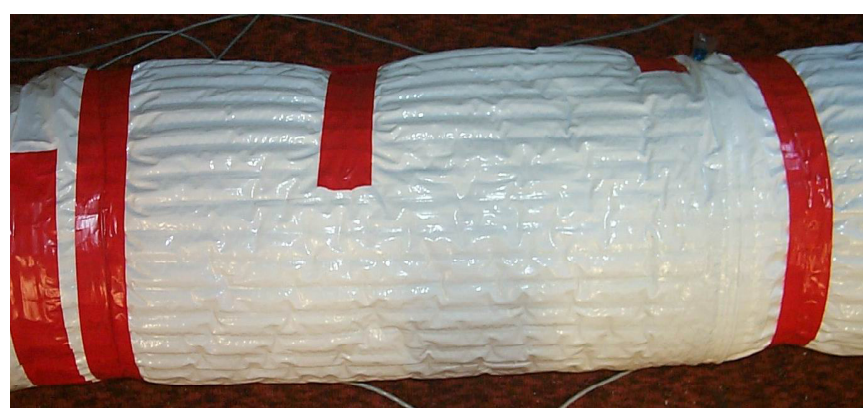

Figure 6. Section of prototype GFP duct.

\section{TEST APPARATUS AND MEASUREMENT PROCEDURES}

The testing was split into two phases. The first phase of testing focused on the comparison testing of the four duct types discussed above. The second phase tested standard flex duct only and was primarily used to clarify potential mixing, boundary layer and stratification issues that were discovered in the first phase. We used temperatures and flow-rates typical of those found in residential systems with a range from $88^{\circ} \mathrm{F}$ to $183^{\circ} \mathrm{F}\left(31^{\circ} \mathrm{C}\right.$ to $\left.84^{\circ} \mathrm{C}\right)$ and 40 to $180 \mathrm{cfm}(19$ to $85 \mathrm{~L} / \mathrm{s})$.

The thermal resistance of the ducts was determined from the interior duct surface area $(A)$, mass flow through the duct $(m)$, the specific heat of air $(C p)$, and the temperature difference between air entering the test section (Tin) and the ambient air (Tamb) and air leaving the test section (Tout) and the ambient air (Tamb). Using standard heat exchanger relationships, the thermal resistance is given by:

$$
R=\frac{A}{m C p \ln \left(\frac{\text { Tout }- \text { Tamb }}{\text { Tin }- \text { Tamb }}\right)}
$$

In the experiments we varied the mass flow rate and the heat supplied to the air to give a range of flow rates and temperatures to examine any trends in thermal performance with these parameters. The ducts were evaluated by blowing heated air through the ducts and measuring the temperature drop along the duct, using the apparatus shown in Figure 7. All the duct test sections were $17 \mathrm{ft}(5.2 \mathrm{~m})$ long. This duct length was limited by the size of our laboratory combined with the length of the nozzle flow-meter and the rest of the test apparatus.

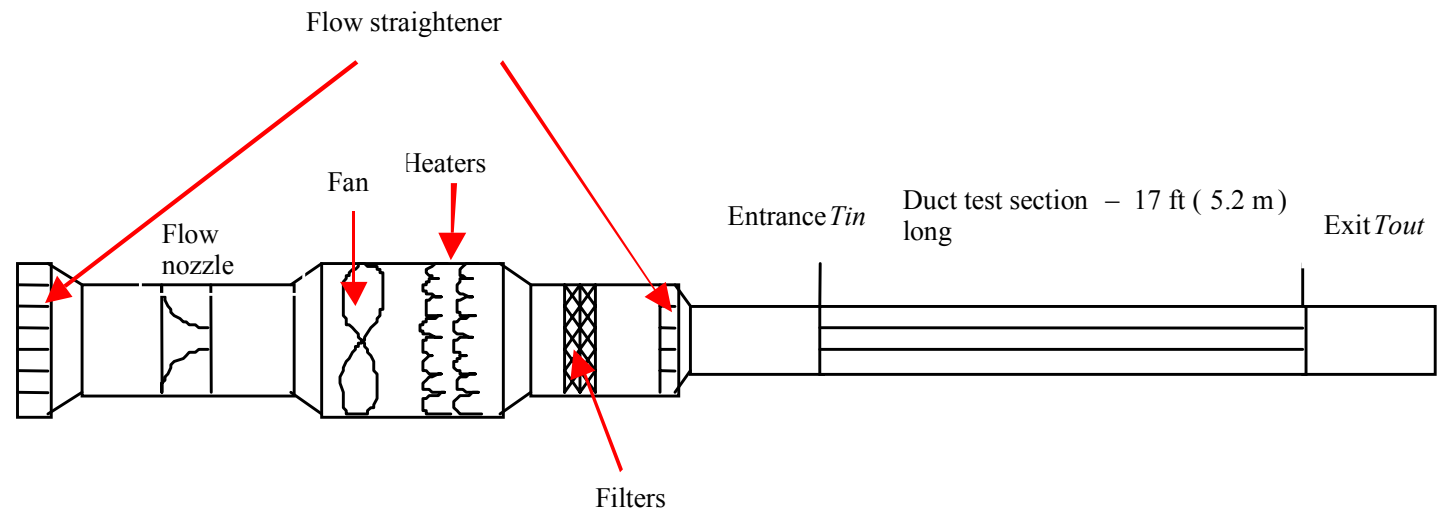

Figure 7. Experimental Apparatus for Phase 1 Tests 


\section{Phase 1: Comparison of GFP duct to standard ducts}

The same length of each of the four duct types (GFP, uninflated GFP, standard insulated flex and uninsulated flex) was used in each experiment. An electric resistance heater was used to heat the air, and a flow nozzle ( $\pm 0.5 \%$ accuracy) was used to measure the air flow through the test apparatus. Static pressure averaging rings were installed at the entry and exit of the duct test section to measure the pressure drop through the test section. We also used an IR thermal imaging camera to examine the surface temperatures of ducts during the tests.

Considerable effort was made to have uniform temperature and air-flow within the ducts. This is important because the heat loss from the test ducts is determined from the difference in temperatures between the inlet and exit of the duct and the mass flow of air through the duct. Although the flow nozzle is good at averaging any flow nonuniformities across the duct cross-section, there is much greater difficulty in determining the mass flow weighted temperature difference across each cross section. Flow rings with a smooth nozzle profile inlet (from a commercial air flow measurement device) were used on the inlet to the test apparatus to give a smooth entry for the air. We added filters and honeycomb flow-straighteners after the heaters. In addition, flow straighteners were placed after the entry and before the flow measurement nozzle. Temperatures were measured using thermistors that have an accuracy of $0.2 \pm^{\circ} \mathrm{F}\left( \pm 0.1^{\circ} \mathrm{C}\right)$. The following air temperatures were measured:

- ambient air temperature in the laboratory (this was continuously monitored during the experiments to see if the laboratory temperature increased during the experiments. In most cases the increases were insignificant (approaching the accuracy limits of our measurements)

- air entering the test section

- air leaving the test section

We did not control the radiative environment for the test ducts, however, the laboratory air and surface temperatures were very close (within $\pm 2^{\circ} \mathrm{F}\left( \pm 1^{\circ} \mathrm{C}\right)$ ) so the radiation heat transfer will then primarily depend on the surface finish of the ducts. During the testing the laboratory air temperature averaged $79^{\circ} \mathrm{F}\left(26^{\circ} \mathrm{C}\right)$ with a variation of only $\pm 2^{\circ} \mathrm{F}\left( \pm 1^{\circ} \mathrm{C}\right)$. Therefore, each duct had the same radiative environment, so that changes in duct surface finish and therefore radiation heat transfer parameters will be included in the overall thermal resistance of the duct. The exterior finish of the GFP ducts was white plastic - with sections of red tape used to hold the GFP sections together. The standard duct had a black plastic/outer layer.

The duct air temperatures, heater power consumption and air flow rates were continuously monitored using a data acquisition system. This gave us the ability to improve test accuracy by using time-averaged data and also to examine the quasi-steady test results. For example, we found that up to 20 minutes of system operation was required to ensure that the initial transient heating of the apparatus was completed. In addition to the thermal and air flow measurements, a few Infrared (IR) images were taken of the ducts during testing to illustrate surface temperature non-uniformities.

A key issue in these experiments is the energy flow in and out of the test sections. The energy flow depends on the integration of the temperature and mass flow across the entry and exit flows of the test section. In these experiments we know the total air flow through the system from the nozzle measurements, but not the velocity distribution across the duct cross sections. The temperatures were measured using thermistors using a data acquisition system. The physical size of the thermistors meant that we could not measure at a large number of locations across the duct cross sections without significantly altering the air flow and temperatures in the duct. Therefore, we needed to optimize the temperature measurements so that the limited number of measurements we made for each experiment would give an accurate estimate of the energy flows when combined with the total flow rate. We did several experiments to determine the temperature distribution across the cross-section at the test section entry. Eleven temperatures were measured on two perpendicular cross sections.

Initially, we found significant differences from location to location, so a flow straightener and filters were added between the heaters and the test section. Even after these additions, there was still a $10^{\circ} \mathrm{F}\left(5^{\circ} \mathrm{C}\right)$ difference between points across the duct. Preliminary tests showed that at the exit of the test section we found that the differences between the edge and centerline were significantly reduced to less than $1^{\circ} \mathrm{F}\left(0.5^{\circ} \mathrm{C}\right)$. This increase in temperature uniformity was probably due to additional flow mixing in the test section due to the surface roughness of the test sections. The effect of these temperature variations will be addressed more thoroughly later in this report. We decided to measure the centerline temperature of the air entering and leaving the test sections as the temperature for use in the thermal resistance calculations. This was chosen because the centerline temperature is the usual reference used for heat transfer calculations for these axially symmetric geometries. In addition, because we are not changing the fan, heater, duct liner or other test apparatus geometries we can assume that the non-uniformities are consistent 
and similar for both duct test samples. A more thorough approach would be to carefully map the air flow and coincident temperatures at many locations within the duct, however, that activity was beyond the scope of this study.

\section{Phase 2: Investigation of Temperature Non-Uniformities}

In this second phase we only tested standard R4.2 insulated flexible duct, and the experiments were focussed on the low flow rates where we had found unusual test results in Phase 1. An experimental apparatus similar to Phase 1 was used, with the same $17 \mathrm{ft}(5.2 \mathrm{~m})$ length of test duct. The differences were that a different fan was used and placed upstream of the flow nozzle, an additional six feet $(2 \mathrm{~m})$ of inflatable lay flat tubing was placed between the heaters and the inlet to the $5 \mathrm{ft}(1.7 \mathrm{~m})$ sheet metal pressure measurement duct sections. For some experiments we added flow resistances in an attempt to make the temperature profiles more uniform. The first flow restriction was a reduction in the diameter of the flexible duct between the heaters and the inlet to the test section. This forced all the flow through a hole approximately one inch $(25 \mathrm{~mm})$ in diameter. A second device used to mix the air was the flow mixer shown in Figure 8, that consisted of a piece of one inch $(25 \mathrm{~mm})$ thick insulation board with three holes each about an inch $(25 \mathrm{~mm})$ in diameter placed midway between the centerline and the edge. This flow mixer was placed four inches upstream of the test section outlet temperature measurements. In conjunction with the flow mixer we replaced the smooth lay flat tubing upstream of the test section with uninsulated flexible ducting with high internal roughness. The objective of this flow mixer was to mix the flows at the centerline and edges of the duct to reduce the thermal boundary layer effects. This device also added turbulence to the flow that makes the downstream temperature and velocity profiles more uniform. These flow mixing problems are recognized in air flow measurement standards, for example ANSI/ASHRAE Standard 41.2, 1992, "Standard Methods for Laboratory Air Flow Measurements" includes several example illustrations of flow mixers and also includes a sketch for a flow sampling manifold for use in large cross section ducts. For the experiments with the added flow restrictions, we also measured the air temperatures one inch $(25 \mathrm{~mm})$ into the duct as well as the centerline temperatures in order to examine how the extra mixing affected the temperature uniformity across the duct.

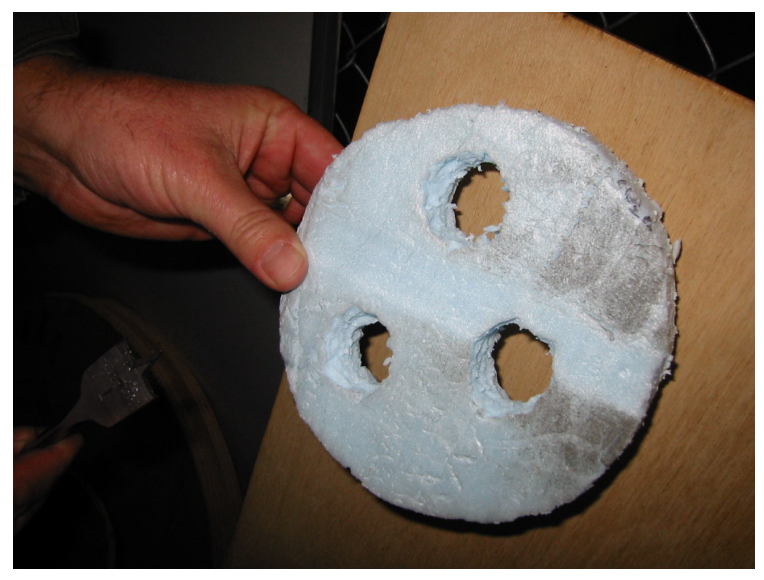

Figure 8. Flow mixer added to Phase 2 apparatus to increase mixing within the duct

\section{EXPERIMENTAL RESULTS}

The experimental data for Phase 1 and Phase 2 are summarized in Appendix 1 and in Appendix 2, respectively. The results are described in the next section.

\section{Phase 1}

The measured inlet and outlet temperatures for the GFP duct tests are shown in Figure 9. These data show the expected lower temperatures at the outlet, and how using more electric heaters results in overall higher experimental temperatures. The figure also shows the temperatures decrease with increasing air flow rate. All of these data follow the trends we expect to see in this experiment. 


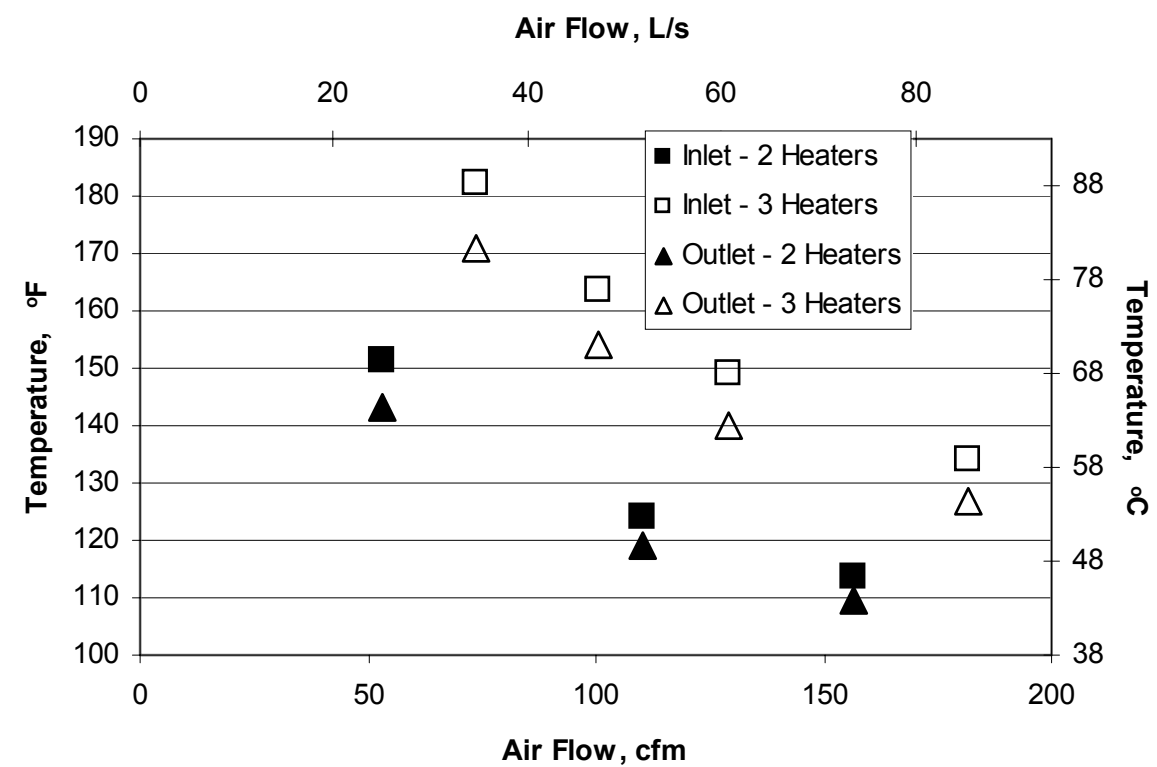

Figure 9. Measured Inlet and Outlet Temperatures for the Gas Filled Plenum Duct using Two and Three Heaters

Figure 10 shows how the calculated thermal resistance (R-value) changed with air flow rate for all the tested ducts. The uninsulated flex duct has the lowest R-value and the standard R4.2 (RSI 0.7) insulated flex duct has the highest R-value (close to its nominal rated value for flow rates above $100 \mathrm{cfm}(47 \mathrm{~L} / \mathrm{s})$ ). The inflated GFP performs better than the uninflated GFP. The data show the general trend of decreasing R-value as the flowrate increases. Some of this can be attributed to the reduced thermal resistance of the interior boundary layer as the flow rate increases, but this is a small effect (a change in internal boundary layer R-value from 0.2 to 0.1 (RSI 0.04 to 0.015 ). At lower flows the measured R-values appear to increase significantly. It is difficult to find a physical explanation for this increase and it is most likely due to experimental uncertainty. This is also suggested by the three tests on the standard R4.2 (RSI 0.7) flexduct that range from R9 to R12 (RSI 1.5 to 2). These unusually large R-values and the large range obtained when repeating the experiments leads us to believe that at low flow rates the experimental errors become too large for any conclusions about duct performance to be inferred from the data. 


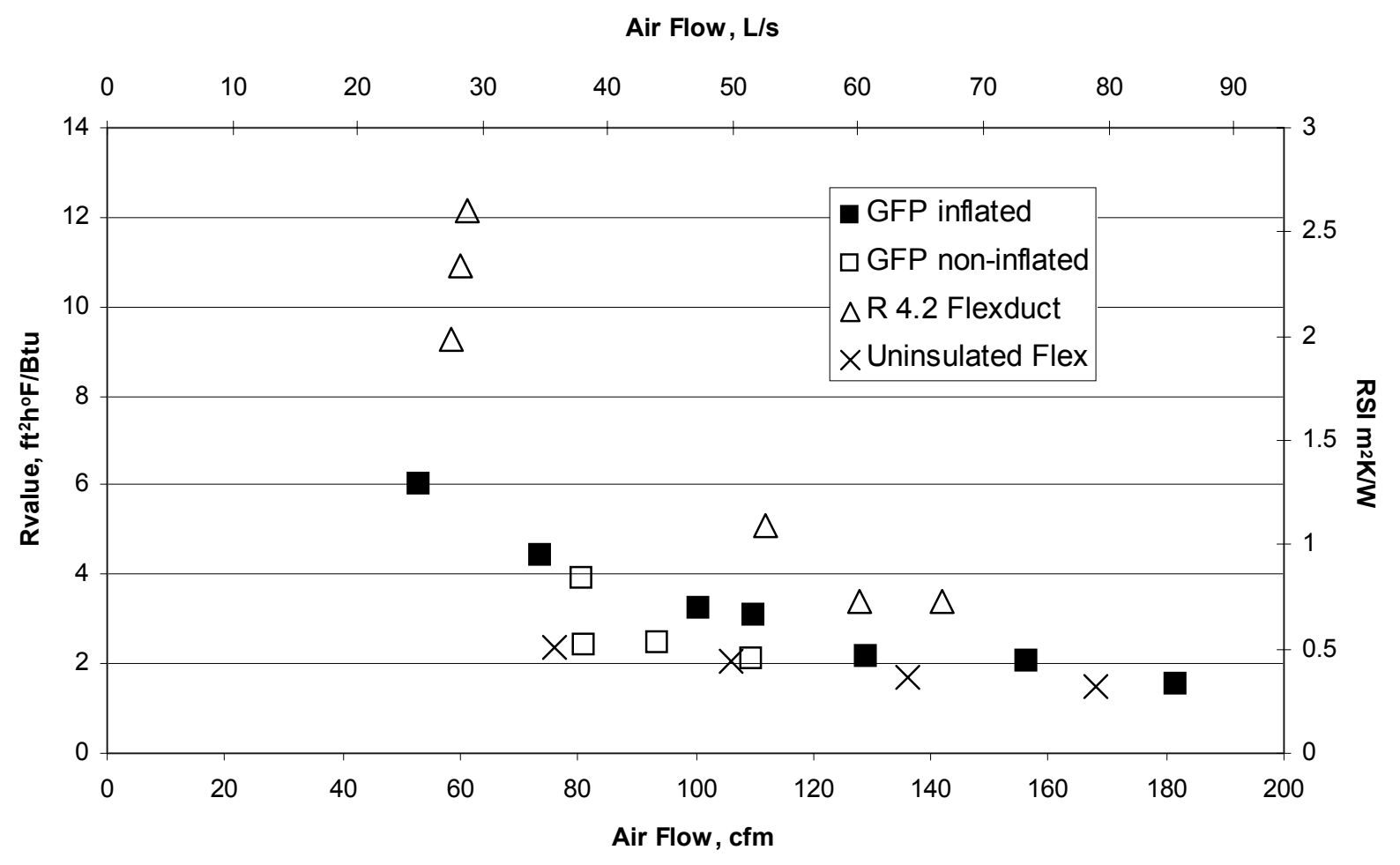

Figure 10. Changing duct thermal resistance with air flow.

\section{Phase 2}

The unusual results at low flows in Phase 1 led us to perform the tests in Phase 2 that were focussed on estimating and minimizing these experimental errors. The possible sources of error were from the measured air flow rates and temperature measurements. Extensive use of the nozzle flow meter in other experiment has shown that it is an extremely reliable device and unlikely to contribute more than its stated accuracy $( \pm 0.5 \%)$ to uncertainty in the flow measurements. The air temperatures were measured with very carefully calibrated thermistors $\left( \pm 0.2^{\circ} \mathrm{F}\right.$ $\left( \pm 0.1^{\circ} \mathrm{C}\right)$ ), however, as stated previously, we found that the temperature varied greatly across the cross section of duct (typically by more than $9^{\circ} \mathrm{F}\left(5^{\circ} \mathrm{C}\right)$ ) and this variation increased at lower flow rates. This means that the measured temperature is very sensitive to sensor placement. It would be possible to obtain a better measure of heat loss from the air by requiring temperature measurements at multiple points in the flow that were weighted by the mass flow rate at each point. Under the time and budget constraints of this study this was not feasible. There is insufficient space across the cross section of the duct to place enough of the temperature sensors required for these experiments, and considerable time would be required if traverses were to be performed. Similarly, the only way to obtain sufficient spatial resolution of mass flow rate would require multiple hot wire traverses or use of a laser Doppler anemometer system.

We repeated the tests using standard R4.2 (RSI 0.7) flex duct over a similar range of flows and air temperatures as in Phase 1. We spent considerable effort to ensure that the temperature sensors were located on the centerline, and we added various levels of mixing to reduce the thermal boundary layer in the duct. For three tests we simultaneously measured at two points: on the centerline and one inch $(25 \mathrm{~mm}$ ) from the duct wall (one third of the way across the radius to the centerline). At both the outlet and inlet typical temperature differences from the centerline to one inch from the duct wall were about $9^{\circ} \mathrm{F}\left(5^{\circ} \mathrm{C}\right)$. These are large variations compared to the temperature drop along duct that ranged from $1^{\circ} \mathrm{F}\left(0.5^{\circ} \mathrm{C}\right)$ to $7^{\circ} \mathrm{F}\left(3.5^{\circ} \mathrm{C}\right)$, which indicates that the most likely source of large errors in these experiments is due to insufficient sampling of the temperature and velocity (mass flow) profiles across the duct. 
Figure 11 shows in more detail how the calculated thermal resistance changed depending on the location of the temperature measurements. Oddly, the addition of the mixer actually made the results worse in these experiments. Without the mixer the edge temperatures led to higher estimates of the insulation value. The centerline temperatures gave consistent results close to the rated value of the insulation over the whole range of tested flows, except after the mixer was inserted. The edge temperatures measured one inch $(25 \mathrm{~mm})$ from the duct wall were lower than the centerline temperatures and showed less temperature change along the duct resulting in higher insulation values.

Figure 12 compares the results for insulated flex duct from the two phases of testing. Figure 12 combines the results shown in Figure 11 and the insulated flex duct results from Figure 10. The results are consistent, with very high calculated thermal resistance at lower flows in both phases. This indicates that the temperature measurements in the first phase exhibit the same errors as in the second phase at low flows.

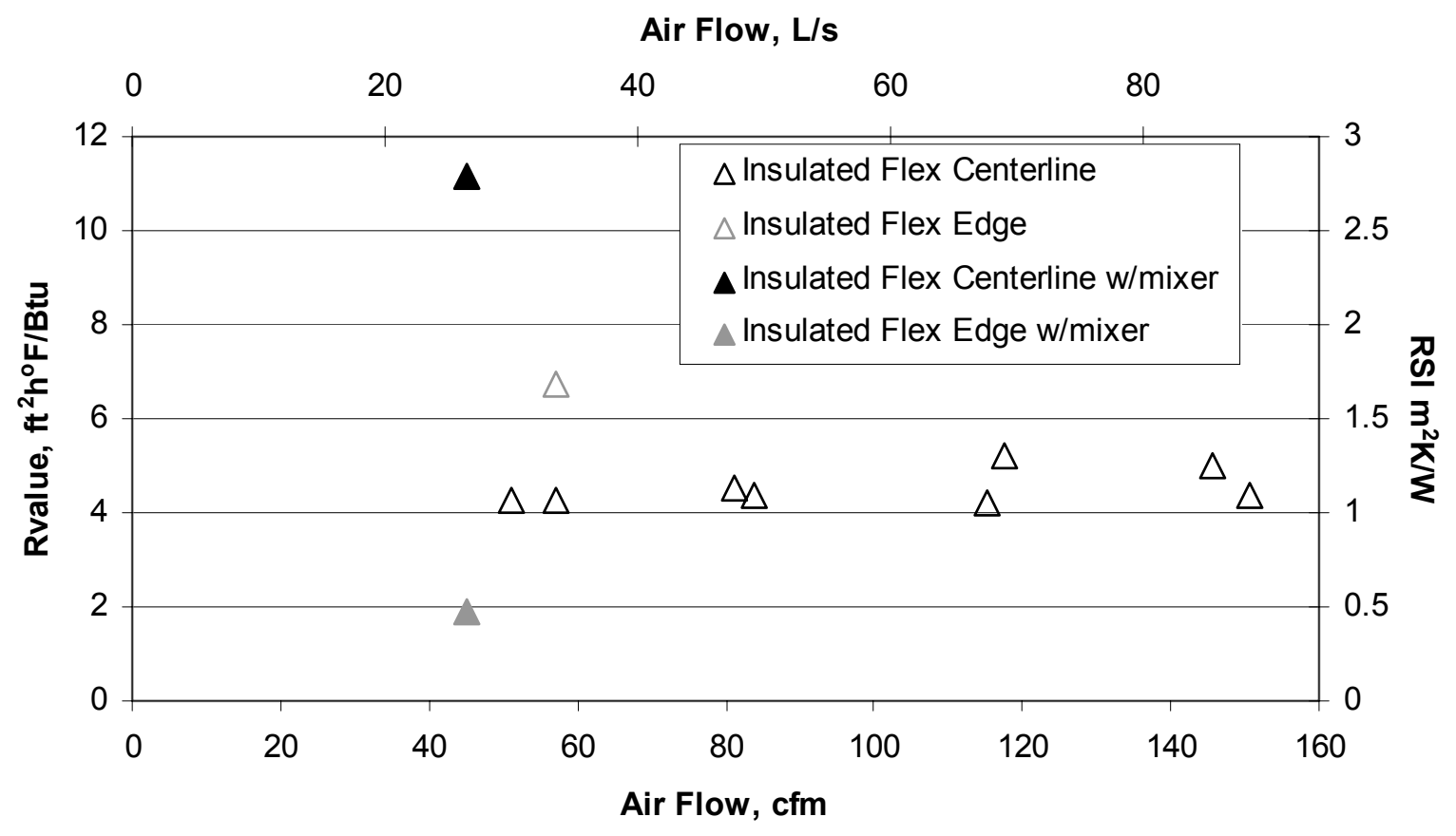

Figure 11. Variability of Measured Duct Insulation Values Depending on Temperature Measurement Location 


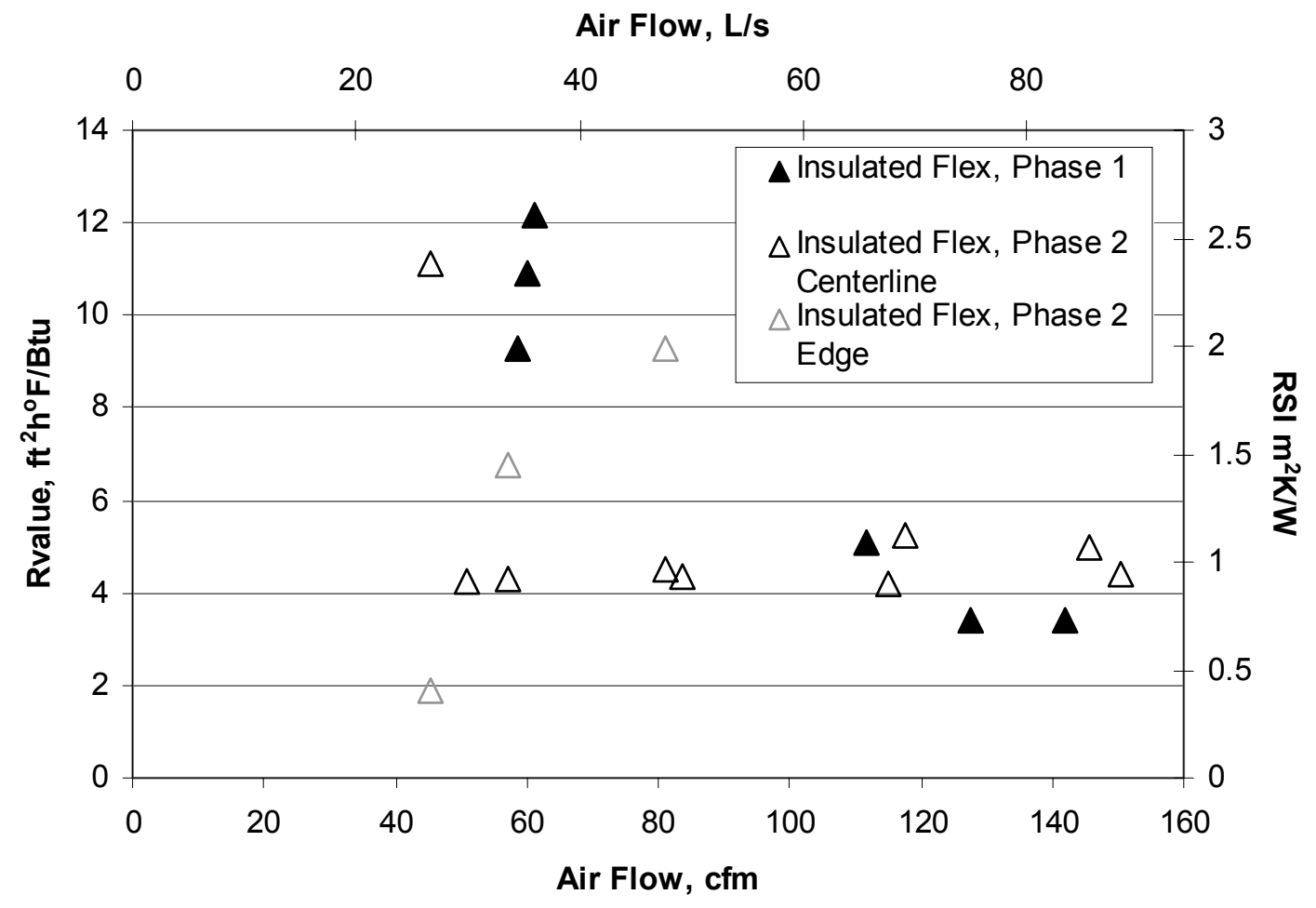

Figure 12. Comparison of Phase 1 and Phase 2 Results for Insulated Flex

Figure 6 showed a typical GFP duct section, where the white surfaces are the exterior of the panels used to fabricate the duct and the red tape was used to hold the sections together. The IR images showed that the taped sections where the GFP was compressed have higher exterior surface temperatures and therefore greater heat loss. An illustration of this is given in Figure 13.
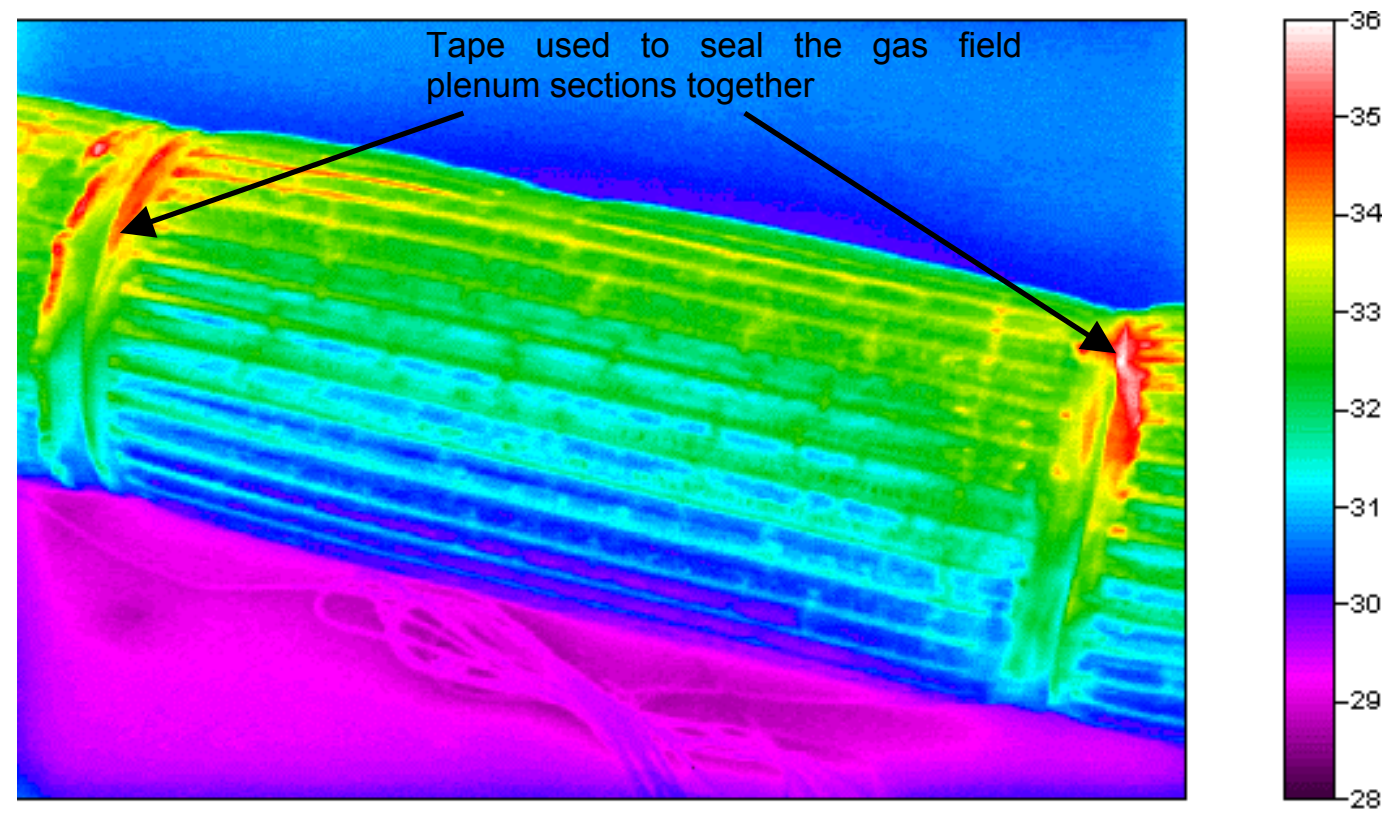

Figure 13. Infrared Picture of the Exterior of the Gas Filled Plenum Duct (scale in ${ }^{\circ} \mathrm{C}$ ) 


\section{SUMMARY}

This study has shown that using an air fill for GFP ducts produces about the same thermal insulation per unit thickness as standard glass fiber duct insulation. It would be possible to increase the GFP thermal resistance using more exotic gases, such as Argon, to fill the panels, but this would add expense (about $\$ 0.07 / \mathrm{L}$ in small quantities required for prototyping, but less in bulk). Another issue with exotic gas fills is that GFPs tend to lose their fill over time. With a normal air fill, the replacement of air with air would not change the insulation value, however, argon replaced by air (or simply lost) would result in large decreases in thermal insulation over time. The loss of air fill in our test sample reduced the insulation level by about $40 \%$. This result shows that it would be important to ensure a good seal when manufacturing the GFP ducts if thermal resistance was to be maintained over the life of the duct. The slight pressurization used in our prototypes was used to provide structural rigidity rather than increasing the insulating value. Previous work at LBNL has shown that Argon fills are retained at neutral pressures, so that it may be possible to have a neutrally Argon filled GFP duct that does not lose its fill and would have a higher thermal resistance than the unfilled ducts we tested in this study. In order for GFP ducts to move beyond the conceptual phase discussed in this study, a potential manufacture needs to put a lot of effort into developing gas-filled components where the material is built with GFP concept specifically in mind.

We examined several potential GFP duct assembly/construction techniques. The use of multiple longitudinal sections, combined with a duct liner (standard spiral flex uninsulated) to prevent collapsing when bent was the simplest to construct. However, given the complexity of even this simplest construction method compared to existing insulated ducts, it is unlikely that this could be a viable method for residential duct systems. Furthermore, the GFP did not offer any discernable space saving advantages for achieving the same thermal resistance with an air fill.

Lastly, we found that the significant variation of temperature across the flow field within the ducts made accurate thermal resistance measurement difficult, particularly at low flow rates. If these experiments are repeated or added to in the future, it will be necessary to perform much more complex and detailed temperature and air flow measurements to more thoroughly map the flow field. These tests would also benefit from the use of more complex mixing devices within the ducts to help make the velocities and temperatures more uniform. One limitation of using the heavy mixing approach, however, is that these mixing devices are not present in real duct installations. It is possible that the short duct runs and multiple joints, connections, bends and other flow disturbing features contribute to greater mixing in actual duct installations in houses, but this requires confirmation through detailed field testing.

\section{ACKNOWLEDGEMENTS}

This work was supported by the Assistant Secretary for Energy Efficiency and Renewable Energy, Building Technologies, of the U.S. Department of Energy under contract No. DE-AC03-76SF00098. The authors would like to thank the following LBNL staff and students who contributed to the tests and provided thoughtful guidance for this study: Darryl Dickerhoff, HowdyGoudey, Dariush Arasteh, and Chuck Hambleton.

\section{REFERENCES}

BOCA. 2003. International Energy Conservation Code. Building Officials and Code Administrators, Country Club Hills, IL.

ANSI/ASHRAE. 1992. Standard 41.2 Standard Methods for Laboratory Air Flow Measurements, ASHRAE, Atlanta, GA. 


\section{APPENDIX 1}

Table A1. Results of laboratory testing to determine the thermal resistance of GFP ducts, standard insulated flexible duct (R4.2) and uninsulated flex duct (with a "silver" metallized foil)

\begin{tabular}{|c|c|c|c|c|c|c|c|c|c|}
\hline Air Flow (cfm) & Air Flow (L/s) & $\begin{array}{c}\text { Tambient } \\
\left({ }^{\circ} \mathrm{C}\right)\end{array}$ & $\begin{array}{c}\text { Tambient } \\
\left({ }^{\circ} \mathrm{F}\right)\end{array}$ & $\begin{array}{l}\text { Tin } \\
\left({ }^{\circ} \mathrm{C}\right)\end{array}$ & $\begin{array}{l}\text { Tin } \\
\left({ }^{\circ} \mathrm{F}\right)\end{array}$ & $\begin{array}{l}\text { Tout } \\
\left({ }^{\circ} \mathrm{C}\right)\end{array}$ & $\begin{array}{l}\text { Tout } \\
\left({ }^{\circ} \mathrm{F}\right)\end{array}$ & $\begin{array}{c}\text { RSI } \\
\left(\mathrm{m}^{20} \mathrm{C} / \mathrm{W}\right)\end{array}$ & $\begin{array}{c}\text { R value } \\
\left(\mathrm{ft}^{2 \mathrm{o}} \mathrm{Fh} / \mathrm{Btu}\right)\end{array}$ \\
\hline \multicolumn{10}{|c|}{ GFP duct inflated 3 heaters } \\
\hline 74 & 35 & 26 & 79 & 83.6 & 182 & 77.1 & 171 & 0.78 & 4.4 \\
\hline 101 & 47 & 26.1 & 79 & 73.1 & 164 & 67.8 & 154 & 0.57 & 3.2 \\
\hline 129 & 61 & 26.4 & 80 & 65.1 & 149 & 60.1 & 140 & 0.38 & 2.2 \\
\hline 181 & 86 & 26.6 & 80 & 56.7 & 134 & 52.8 & 127 & 0.27 & 1.5 \\
\hline \multicolumn{10}{|c|}{ GFP duct inflated 2 heaters } \\
\hline 110 & 52 & 26.4 & 80 & 51.2 & 124 & 48.5 & 119 & 0.54 & 3.1 \\
\hline 156 & 74 & 26.1 & 79 & 45.3 & 114 & 43.1 & 110 & 0.36 & 2.0 \\
\hline \multicolumn{10}{|c|}{ GFP Duct non-inflated 2 Heaters } \\
\hline 81 & 38 & 21.2 & 70 & 53 & 127 & 49.3 & 121 & 0.69 & 3.9 \\
\hline \multicolumn{10}{|c|}{ GFP Duct non-inflated 3 Heaters } \\
\hline 81 & 38 & 21.4 & 71 & 68.8 & 156 & 60.2 & 140 & 0.42 & 2.4 \\
\hline 110 & 52 & 21.4 & 71 & 66.3 & 151 & 59.4 & 139 & 0.38 & 2.1 \\
\hline \multicolumn{10}{|c|}{ Flexible insulated duct 3 heaters } \\
\hline 59 & 28 & 19.5 & 67 & 78.7 & 174 & 74.6 & 166 & 1.63 & 9.3 \\
\hline 112 & 53 & 18.4 & 65 & 56.1 & 133 & 53.6 & 128 & 0.90 & 5.1 \\
\hline 142 & 67 & 19 & 66 & 51.1 & 124 & 48.6 & 119 & 0.60 & 3.4 \\
\hline \multicolumn{10}{|c|}{ Flexible insulated duct 2 heaters } \\
\hline 60 & 28 & 20.2 & 68 & 51.3 & 124 & 49.5 & 121 & 1.92 & 10.9 \\
\hline 61 & 29 & 19.8 & 68 & 51.2 & 124 & 49.6 & 121 & 2.14 & 12.2 \\
\hline 128 & 60 & 20 & 68 & 38.6 & 101 & 37 & 99 & 0.60 & 3.4 \\
\hline \multicolumn{10}{|c|}{ Uninsulated flexible duct (metallized foil coating) } \\
\hline 76 & 36 & 16.3 & 61 & 68.6 & 155 & 58.5 & 137 & 0.42 & 2.4 \\
\hline 106 & 50 & 16.4 & 62 & 57.9 & 136 & 51.1 & 124 & 0.36 & 2.1 \\
\hline 136 & 64 & 16.7 & 62 & 50.9 & 124 & 45.6 & 114 & 0.30 & 1.7 \\
\hline 168 & 79 & 16.9 & 62 & 46.6 & 116 & 42.3 & 108 & 0.26 & 1.5 \\
\hline
\end{tabular}


APPENDIX 2

Table A2. Phase 2 Test Results Summary for Standard Flex Duct

\begin{tabular}{|c|c|c|c|c|c|c|c|c|c|c|c|c|c|}
\hline $\begin{array}{l}\text { Air } \\
\text { Flow } \\
\text { (cfm) }\end{array}$ & $\begin{array}{l}\text { Air } \\
\text { Flow } \\
(\mathrm{L} / \mathrm{s})\end{array}$ & $\begin{array}{l}\text { Tamb } \\
\left({ }^{\circ} \mathrm{C}\right)\end{array}$ & $\begin{array}{l}\text { Tamb } \\
\left({ }^{\circ} \mathrm{F}\right)\end{array}$ & $\begin{array}{l}\text { Tin, } \\
\mathrm{c} / \mathrm{l} \\
\left({ }^{\circ} \mathrm{C}\right)\end{array}$ & $\begin{array}{l}\text { Tin, } \\
\mathrm{c} / 1 \\
\left({ }^{\circ} \mathrm{F}\right)\end{array}$ & $\begin{array}{l}\text { Tout, } \\
\mathrm{c} / \mathrm{l} \\
\left({ }^{\circ} \mathrm{C}\right)\end{array}$ & $\begin{array}{l}\text { Tout, } \\
\mathrm{c} / 1 \\
\left({ }^{\circ} \mathrm{F}\right)\end{array}$ & $\begin{array}{l}\text { Tin, } \\
25 \mathrm{~mm} \\
\text { from } \\
\text { duct wall } \\
\left({ }^{\circ} \mathrm{C}\right)\end{array}$ & $\begin{array}{l}\text { Tin, } \\
25 \mathrm{~mm} \\
\text { from } \\
\text { duct wall } \\
\left({ }^{\circ} \mathrm{F}\right)\end{array}$ & $\begin{array}{l}\text { Tout, } \\
25 \mathrm{~mm} \\
\text { from } \\
\text { duct wall } \\
\left({ }^{\circ} \mathrm{C}\right)\end{array}$ & $\begin{array}{l}\text { Tout, } \\
25 \mathrm{~mm} \\
\text { from } \\
\text { duct wall } \\
\left({ }^{\circ} \mathrm{F}\right)\end{array}$ & $\begin{array}{l}\text { RSI } \\
\left(\mathrm{m}^{2 \circ} \mathrm{C} / \mathrm{W}\right)\end{array}$ & $\begin{array}{l}\mathrm{R} \\
\left(\mathrm{ft}^{20} \mathrm{Fh} / \mathrm{Btu}\right)\end{array}$ \\
\hline \multicolumn{14}{|c|}{ One heater } \\
\hline 145 & 68.7 & 13.6 & 56.5 & 28.5 & 83.3 & 28 & 82.4 & & & & & 0.88 & 5.0 \\
\hline 118 & 55.5 & 13.5 & 56.3 & 31.2 & 88.2 & 30.5 & 86.9 & & & & & 0.92 & 5.2 \\
\hline 84 & 39.6 & 13.5 & 56.3 & 36.4 & 97.5 & 34.9 & 94.8 & & & & & 0.77 & 4.4 \\
\hline 51 & 24.1 & 13.5 & 56.3 & 45.8 & 114.4 & 42.3 & 108.1 & & & & & 0.75 & 4.3 \\
\hline \multicolumn{14}{|c|}{ Two heaters } \\
\hline 151 & 71.1 & 14 & 57.2 & 43.8 & 110.8 & 42.7 & 108.9 & & & & & 0.77 & 4.4 \\
\hline 115 & 54.4 & 13.7 & 56.7 & 51.6 & 124.9 & 49.7 & 121.5 & 45.7 & 114.3 & & & 0.74 & 4.2 \\
\hline \multicolumn{14}{|c|}{ Two heaters with added flow restriction after heaters } \\
\hline 81 & 38.3 & 13.2 & 55.8 & 39.2 & 102.6 & 37.5 & 99.5 & 34.8 & 94.6 & 34.1 & 93.4 & 0.80 & 4.5 \\
\hline 57 & 27.0 & 13.3 & 55.9 & 44.4 & 111.9 & 41.4 & 106.5 & 37.4 & 99.3 & 35.9 & 96.6 & 0.76 & 4.3 \\
\hline \multicolumn{14}{|c|}{ Two heaters with added flow restriction after heaters and flow mixer before outlet temperature measurements } \\
\hline 45 & 21.4 & 13.5 & 56.3 & 44.7 & 112.5 & 43.2 & 109.8 & 44.2 & 111.6 & 36.4 & 97.5 & 1.97 & 11.2 \\
\hline \multicolumn{14}{|c|}{ No heat } \\
\hline 47 & 22.2 & 13.1 & 55.6 & 13.6 & 56.5 & 13.6 & 56.5 & 13.8 & 56.8 & 13.5 & 56.3 & & \\
\hline
\end{tabular}

Table A3. Phase 2 Test Results Comparing Temperature Measurement Locations

\begin{tabular}{|c|c|c|c|c|c|c|c|}
\hline & & \multicolumn{2}{|c|}{ Using Centerline Temperatures } & \multicolumn{2}{|c|}{ Using Near Wall Temperatures } & \multicolumn{2}{|c|}{ Using Average Temperatures } \\
\hline Air Flow (cfm) & Air Flow (L/s) & $\mathrm{RSI}\left(\mathrm{m}^{20} \mathrm{C} / \mathrm{W}\right)$ & $\mathrm{R}\left(\mathrm{ft}^{20} \mathrm{Fh} / \mathrm{Btu}\right)$ & $\mathrm{RSI}\left(\mathrm{m}^{20} \mathrm{C} / \mathrm{W}\right)$ & $\mathrm{R}\left(\mathrm{ft}^{20} \mathrm{Fh} / \mathrm{Btu}\right)$ & $\mathrm{RSI}\left(\mathrm{m}^{20} \mathrm{C} / \mathrm{W}\right)$ & $\mathrm{R}\left(\mathrm{ft}^{20} \mathrm{Fh} / \mathrm{Btu}\right)$ \\
\hline \multicolumn{8}{|c|}{ Two heaters with added flow restriction after heaters } \\
\hline 81 & 38.3 & 0.80 & 4.5 & 1.6 & 9.3 & 1.0 & 6.0 \\
\hline 57 & 27.0 & 0.76 & 4.3 & 1.2 & 6.8 & 0.9 & 5.1 \\
\hline \multicolumn{8}{|c|}{ Two heaters with added flow restriction after heaters and flow mixer before outlet temperature measurements } \\
\hline 45 & 21.4 & 1.97 & 11.2 & 0.3 & 1.9 & 0.6 & 3.4 \\
\hline
\end{tabular}

